\title{
Evolution of the microstructure in nanocrystalline copper electrodeposits during room temperature storage
}

Pantleon, Karen; Somers, Marcel A. J.

Published in:

Zeitschrift für Kristallographie - Crystalline Materials

Publication date:

2007

Document Version

Publisher's PDF, also known as Version of record

Link back to DTU Orbit

Citation $(A P A)$ :

Pantleon, K., \& Somers, M. A. J. (2007). Evolution of the microstructure in nanocrystalline copper

electrodeposits during room temperature storage. Zeitschrift für Kristallographie - Crystalline Materials, 2(suppl. 26), 261-266.

\section{General rights}

Copyright and moral rights for the publications made accessible in the public portal are retained by the authors and/or other copyright owners and it is a condition of accessing publications that users recognise and abide by the legal requirements associated with these rights.

- Users may download and print one copy of any publication from the public portal for the purpose of private study or research.

- You may not further distribute the material or use it for any profit-making activity or commercial gain

- You may freely distribute the URL identifying the publication in the public portal

If you believe that this document breaches copyright please contact us providing details, and we will remove access to the work immediately and investigate your claim 


\title{
Evolution of the microstructure in nanocrystalline copper electrodeposits during room temperature storage
}

\author{
Karen Pantleon*, Marcel A.J. Somers
}

Technical University of Denmark, Department of Manufacturing Engineering and Management, Kemitorvet, b. 204, DK - 2800 Kgs. Lyngby, Denmark "pantleon@ipl.dtu.dk

Keywords: copper, electrochemical deposition, texture, crystallite size, electrical resistivity.

\begin{abstract}
The microstructure evolution in copper electrodeposits at room temperature (selfannealing) was investigated by means of X-ray diffraction analysis and simultaneous measurement of the electrical resistivity as a function of time. In-situ studies were started immediately after electrodeposition and continued with an unprecedented time resolution until stationary values of the recorded data were obtained. Independent of the copper layer thickness, the as-deposited microstructure consisted of nanocrystalline grains with orientation dependent crystallite sizes. Orientation dependent grain growth, crystallographic texture changes by multiple twinning and a decrease of the electrical resistivity occurred as a function of time at room temperature. The kinetics of self-annealing is strongly affected by the layer thickness: the thinner the layer the slower is the microstructure evolution and self-annealing is suppressed completely for a thin layer of $0.4 \mu \mathrm{m}$.
\end{abstract}

\section{Introduction}

$\mathrm{Cu}$ is the dominant material for interconnects in microelectronics, due to its superior properties like low electrical resistivity, high thermal conductivity and good electromigration resistance. Electrochemical deposition has become the method of choice for manufacturing functional thin $\mathrm{Cu}$ layers, because it provides excellent filling behaviour for small vias and trenches as required for the ongoing miniaturization of advanced microelectronic devices [1]. Electrochemical deposition of $\mathrm{Cu}$ has a long tradition and $\mathrm{Cu}$ electrodeposits have been the subject of manifold investigations of the microstructure and related properties in dependence on the deposition process (e.g. [2]). Frequently, it has been reported that the microstructure of as-deposited $\mathrm{Cu}$ layers is not stable at room temperature, e.g. [3-5]. This has become of special importance since the era of $\mathrm{Cu}$ interconnects. This so-called self-annealing of $\mathrm{Cu}$ layers has a dramatic effect on the functionality and reliability of microelectronic components, but thorough understanding of the driving force(s) and the mechanisms of the microstructure evolution and quantitative modelling of the kinetics is still lacking. 
In the present work, self-annealing of electrochemically deposited $\mathrm{Cu}$ layers at room temperature is investigated in-situ by means of X-ray diffraction analysis and simultaneous measurements of the electrical resistivity.

\section{Experimental}

$\mathrm{Cu}$ layers with thicknesses ranging from less than a micrometer up to a few micrometers were deposited from a commercially available acidic electrolyte (UBAC ${ }^{\mathrm{TM}} \mathrm{ER}$ ). Deposition was carried out onto Si-wafers, which prior to electrodeposition had been coated with a thin double layer of $\mathrm{Ti}$ and $\mathrm{Au}$ as a plating base.

Immediately after deposition investigations of the evolving microstructure were started and continued until stabilization of the microstructure was indicated by the recorded data. X-ray diffraction (XRD) was performed repeatedly and combined with simultaneous measurements of the electrical resistivity. A diffractometer D8 Discover Bruker AXS was applied with Cu$\mathrm{K} \alpha$ radiation for the measurement of diffraction line profiles corresponding to 111 and 200 diffracting lattice planes. With a step size of $0.02^{\circ} 2 \Theta$ about every 15 minutes 111 and 200 line profiles were recorded. Measured line profiles were fitted with a pseudo-Voigt function and corrected for instrumental broadening [6] applying a Si powder reference (NIST 640c). At selected times during the course of self-annealing quarters of 111, 200 and 311 pole figures were measured and, after correction for background and defocusing applying a $\mathrm{Cu}$ powder sample, the crystallographic texture was quantified by calculating the orientation distribution function (assuming rotational symmetry of the pole figures) with the software package LaboTex from LaboSoft Krakow, Poland. Simultaneous to XRD the electrical resistivity was recorded in one minute intervals with a Tinsley Micro Ohmmeter 5891. The experimental set-up is seen in figure 1.

Details on the electrochemical deposition process and the in-situ experiments were provided elsewhere $[7,8]$.

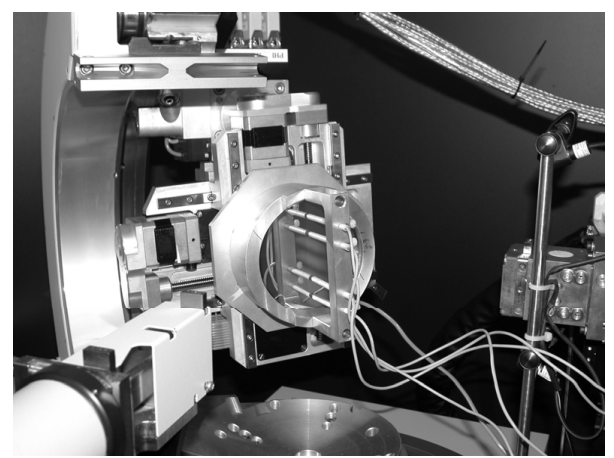

Figure 1. Experimental set-up for the in-situ study of self-annealing in electrochemically deposited copper layers. 


\section{Results and discussion}

The electrical resistivity measurements clearly indicate that the electrodeposited copper layers are not stable at room temperature: a considerable decrease of the electrical resistivity of, totally, about $16 \%$ of the initial resistivity for the layers with thicknesses above one micrometer, was observed as a function of time. Figure 2 shows that the kinetics of the resistivity changes is strongly depending on the layer thickness; the thicker the $\mathrm{Cu}$ layers the faster self-annealing occurs. For the thickest $\mathrm{Cu}$ layers the electrical resistivity stabilizes already after a few days, while for the layers with thicknesses less than one micrometer no stabilization was observed even within several months after deposition [8].

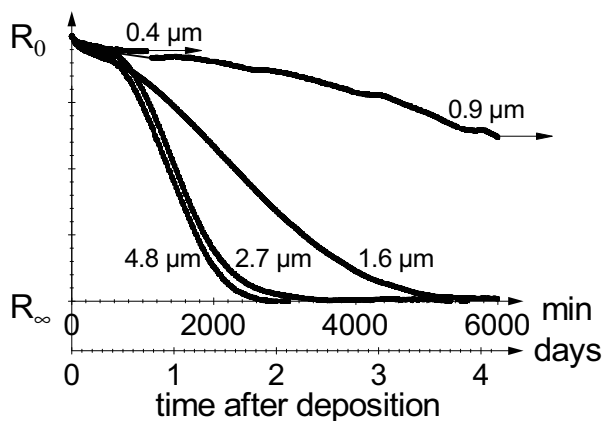

Figure 2. Electrical resistivity $R$ as a function of time after deposition of Cu-films with different thicknesses. The resistivity decreases from the initial value $R_{0}$ to a stable value at room temperature $R_{\infty}$ The arrows indicate that the resistivity did not stabilize for the low film thicknesses.

Electrical resistivity measurements straightforwardly indicate whether self-annealing occurs at all as well as its time scale. However, it is not possible to relate the observed resistivity changes to particular microstructural changes, since the electrical resistivity reflects a variety of microstructural features in terms of various lattice defects. For example, grain boundaries strongly affect the resistivity, but not only the total number of grain boundaries (i.e. grain size), but also the character of grain boundaries is of importance.

From fitting the measured XRD line profiles with a pseudo-Voigt function, it was observed that all diffraction lines were of pure Lorentzian type and the line widths (integral breadths, $\beta$ ) can be considered a direct measure of the crystallite size, $D$, i.e. the size of grains and subgrains. Applying the single line approach [9]

$$
\mathrm{D}=\frac{\lambda}{\beta_{L} \cos \Theta}
$$

( $\Theta$ - Bragg angle, $\lambda$ - X-ray wavelength) the size of $<111>$ and $<100>$ oriented crystallites was calculated from the line profiles measured as a function of time after deposition (cf. figure 3). Figure 3 shows that the as-deposited $\mathrm{Cu}$ layers consist of nanocrystalline grains, whose actual dimensions (in the direction of the diffraction vector) depend on grain orientation. Independent of the $\mathrm{Cu}$ layer thickness, the $<111>$ oriented crystallites are with sizes of about $50 \mathrm{~nm}$ significantly larger than the only $15 \mathrm{~nm}$ sized $<100>$ oriented crystallites. The 
as-deposited nanocrystalline grains grow as a function of time and the growth kinetics was found to depend strongly on the $\mathrm{Cu}$ layer thickness. In agreement with the results obtained from electrical resistivity measurements, the thicker the layers the faster grain growth starts. It should be noted that from the present XRD investigation grain sizes larger than say 200 $\mathrm{nm}$ cannot be determined; the limiting factor in this respect is the instrumental broadening of the X-ray optics. Therefore, it cannot be concluded whether a stable grain size has actually been reached and what the final stable grain size is. Nevertheless the stable grain size for the $4.8 \mu \mathrm{m}$ thick deposit appears to be largest. This is confirmed by electron back scatter diffraction, which reveals that the average grain size after self-annealing depends on the layer thickness [10].
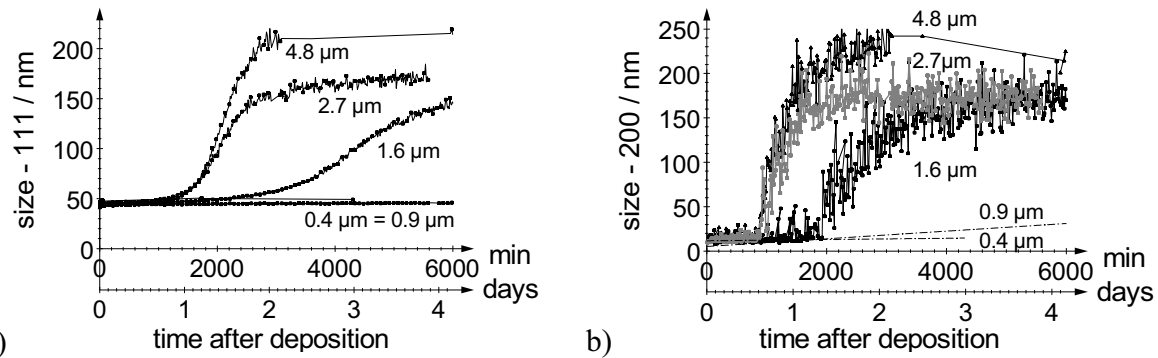

Figure 3. Crystallite size calculated from the broadening of 111 (a) and 200 (b) diffraction lines measured as a function of time after deposition of Cu layers with different thicknesses.

As observed in figures 3 and 4, the kinetics of grain growth depends furthermore on the orientation of the grains. The smaller $<100>$ oriented grains start to grow first and after some time, dependent on the layer thickness (see above), they exceed the size of the initially larger $<111>$ oriented grains, which at that time are still unchanged in the as-deposited state. Obviously, grains with $<111>$ orientation do not grow before the $<100>$ oriented grains have reached a certain size.

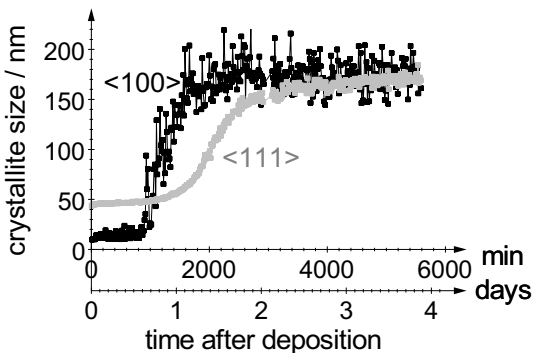

Figure 4. Dependence of the grain growth kinetics on the grain orientation (<111> grains - grey, <100> grains - black) shown for the example of the $2.7 \mu \mathrm{m}$ thick layer from figures $3 a$ and $3 b$.

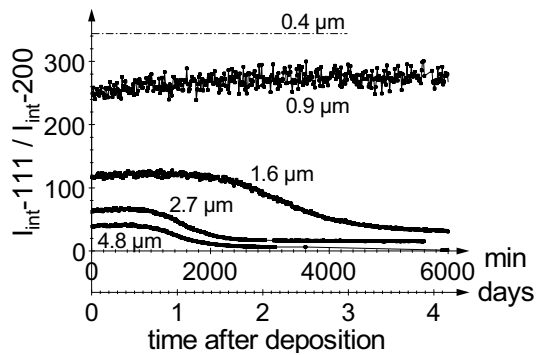

Figure 5. Integrated intensity ratio ( $I_{\text {int }}{ }^{-}$ $111 / I_{\text {int }}$-200) of 111 and 200 line profiles measured as a function of time after deposition of $\mathrm{Cu}$ layers with different thicknesses. 
Additional to the widths of the measured diffraction lines, also the integrated intensities provide information on the microstructure evolution at room temperature. Figure 5 shows the ratio between the integrated intensities determined for the 111 and 200 diffraction lines as a function of time. Comparison with the theoretical intensity ratio of $\mathrm{I}_{\mathrm{int}}-111 / \mathrm{I}_{\mathrm{int}}-200=2.35$ (cf. JCPDS 85-1326), as confirmed from the texture-free standard sample, reveals that the asdeposited $\mathrm{Cu}$ layers exhibits a strong $<111>$ texture, which is the stronger the thinner the $\mathrm{Cu}$ layer (the fibre nature of the $<111>$ texture was confirmed by thorough texture analysis clearly indicating rotational symmetry of the measured pole figures, cf. figure 6). As a function of time at room temperature the ratio $\mathrm{I}_{\mathrm{int}}-111 / \mathrm{I}_{\mathrm{int}}-200$ first remains constant before a drastic decrease is observed (cf. Fig. 5), which is mainly caused by a decreasing integrated intensity of the 111 diffraction lines. This indicates that the as-deposited $\langle 111\rangle$ fibre texture becomes considerably weaker with time. Quantitative texture analysis revealed that a decreasing orientation density of the $<111>$ texture is accompanied by the development of various minor texture components, which can be identified as twin orientations of the original $<111>$ orientation [7]. The kinetics of the change of crystallographic texture is the faster the thicker the $\mathrm{Cu}$ layer. For layers with a thickness of a few micrometers the texture change occurred within the first few days after deposition; in contrast, for the layers with thickness less than one micrometer the texture changed very slowly and after several months finally becomes as weak as the crystallographic texture observed after self-annealing of the thicker layers [8]. In contrast, for the $0.4 \mu \mathrm{m}$ thick $\mathrm{Cu}$ layer no indications of self-annealing were observed at all within one year after deposition. As shown in table 1, even one year after deposition, the same ratio of integrated intensities was measured for this sample indicating that the strong as-deposited $<111>$ texture remained stable for this $\mathrm{Cu}$ layer. For the samples where self-annealing occurred the final stable crystallographic texture appears to be almost independent of the layer thickness (cf. table 1).
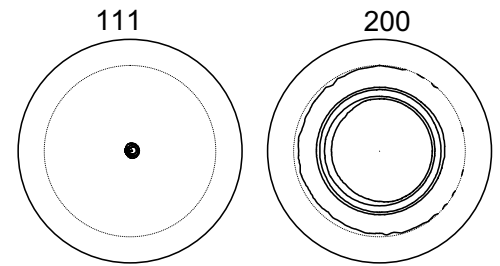

Figure 6. Pole figures measured for the $0.4 \mu \mathrm{m}$ thick Cu layer. The total maxima of the pole density in the center of the 111 pole figure and intensity rings at $54.7^{\circ}$ in the 200 pole figure indicate the presence of $a<111>$ fibre texture.

Table 1: Ratio between the integrated intensities of 111 and 200 diffraction lines asdeposited and about one year after deposition of Cu layers with different thicknesses. Additionally, the volume fraction of the $<111>$ fibre texture is given for samples stored one year at room temperature.

\begin{tabular}{|l|l|c|c|c|c|c|}
\hline thickness & $0.4 \mu \mathrm{m}$ & $0.9 \mu \mathrm{m}$ & $1.6 \mu \mathrm{m}$ & $2.7 \mu \mathrm{m}$ & $4.8 \mu \mathrm{m}$ \\
\hline as-deposited & $\mathrm{I}_{\text {int }}-111 / \mathrm{I}_{\text {int }}-200$ & 344 & 251 & 119 & 64 & 40 \\
\hline \multirow{2}{*}{ after one year } & $\mathrm{I}_{\text {int }}-111 / \mathrm{I}_{\text {int }}-200$ & 338 & 14 & 21 & 10 & 6 \\
\cline { 2 - 8 } & $\mathrm{VF}<111>$ & $41 \%$ & $9.0 \%$ & $7.5 \%$ & $4.4 \%$ & $3.8 \%$ \\
\hline
\end{tabular}




\section{Summary and conclusions}

The evolution of the microstructure in electrochemically deposited $\mathrm{Cu}$ layers at room temperature has been investigated in-situ with X-ray diffraction and simultaneous electrical resistivity measurements. Both experimental procedures revealed that the kinetics of selfannealing is strongly affected by the thickness of the $\mathrm{Cu}$ layers: self-annealing is considerably retarded for layer thicknesses less than one micrometer. While changes of the electrical resistivity represent the overall response of the layers on self-annealing, microstructural details in terms of the size and preferred orientation of grains as well as the kinetics of grain growth including its dependence on grain orientation and the kinetics of the texture development is provided by in-situ XRD. The applied experimental procedure is in particular suitable since it yields information on the real as-deposited state immediately after deposition and allows monitoring the microstructure evolution with a reasonable time resolution.

The results revealed that self-annealing occurs within a period of a few days up to several months after deposition depending on the thickness of the $\mathrm{Cu}$ layers. For a very thin layer no sign of self-annealing was found. For thicker layers, self-annealing appears as a function of time at room temperature in terms of a considerable growth of the as-deposited nanocrystalline grains, a drastic weakening of the as-deposited $\langle 111>$ fibre texture and a decrease of the electrical resistivity.

\section{References}

1. Dubin, V.M., 2003, Microelectronic Engineering, 70, 461.

2. Winand, R., 2000, in: Electrochemical Technology Applications in Electronics. Electrochem. Soc. Proc. vol 99-34, edited by L.T. Romankiw et al., pp. 411-425.

3. Lagrange S., Brongersma S.H., Judelewicz M., Saerens A., Vervoort I., Richard E., Palmans R., Maex K., 2000, Microelctronic Eng., 50, 449.

4. Militzer, M., Freundlich, P., Bizzotto, D., 2004, Mater. Sci. Forum, 467-470, 1339.

5. Stangl, M., Acker, J., Ditel, V., Gruner, W., Hoffmann, V., Wetzig, K., 2005, Microelectronic Engineering, 82, 189.

6. J.I. Langford, 1978, J. Appl. Cryst., 11, 10-14.

7. Pantleon, K., Somers, M.A.J., 2006, Scripta Materialia, 55, 283.

8. Pantleon, K., Somers, M.A.J., 2006, J. Appl. Phys., 100, 114319.

9. De Keijser, T.H., Langford, J.I., Mittemeijer, E.J., Vogels, A.B.P., 1982, J. Appl. Cryst., 15, 308.

10. Pantleon, K., Gholinia, A., Somers, M.A.J., 2007, in preparation.

Acknowledgements. The authors are grateful to the Danish Research Council for Technology and Production Sciences (FTP grant 26-03-0276) for financial support to the present work. 